OPEN ACCESS

Edited by:

Ying Li,

China Earthquake Administration,

China

Reviewed by:

Joern Lauterjung,

Helmholtz Centre Potsdam, Germany Giovanni Martinelli,

National Institute of Geophysics and Volcanology, Italy

*Correspondence: Alexandru Szakács szakacs@sapientia.ro

Specialty section:

This article was submitted to Geohazards and Georisks, a section of the journal Frontiers in Earth Science

Received: 02 April 2020 Accepted: 03 December 2020

Published: 15 January 2021

Citation:

Szakács A (2021) Precursor-Based Earthquake Prediction Research: Proposal for a ParadigmShifting Strategy.

Front. Earth Sci. 8:548398. doi: 10.3389/feart.2020.548398

\section{Precursor-Based Earthquake Prediction Research: Proposal for a Paradigm-Shifting Strategy}

\author{
Alexandru Szakács * \\ Department of Endogene Processes, Natural Hazard and Risk, Romanian Academy, Institute of Geodynamics, Bucharest, \\ Romania
}

The article discusses the controversial topic of the precursor-based earthquake prediction, based on a personal perspective intending to stir the current still waters of the issue after twenty years have passed since the influential debate on earthquake prediction hosted by Nature in 1999. The article challenges the currently dominant pessimistic view on precursor-based earthquake prediction resting on the "impossible in principle" paradigm. Instead, it suggests that a concept-based innovative research strategy is the key to obtain significant results, i.e., a possible paradigm shift, in this domain. The basic concept underlying such a possible strategy is the "precursory fingerprint" of individual seismic structures derived from the uniqueness of the structures themselves. The aim is to find as many unique fingerprints as possible for different seismic structures worldwide, covering all earthquake typologies. To achieve this, a multiparameter approach involving all possible sensor types (physical, chemical, and biological) of the highest available sensitivity and artificial intelligence could be used. The findings would then be extrapolated to other similar structures. One key issue is the emplacement location of the sensor array in privileged "sensitive" Earth surface sites (such as volcanic conduits) where the signal-to-noise ratio is maximized, as suggested in the article. The strategy envisages three stages: experimental phase, validation, and implementation. It inherently could be a costly, multidisciplinary, international, and long-term (i.e., multidecade) endeavor with no guaranteed success, but less adventurous and societally more significant to the currently running and well-funded SETI Project.

Keywords: earthquake prediction, precursor signal, paradigm shift, strategy, sensors, experiment

\section{INTRODUCTION}

"Short-term earthquake prediction is the only useful and meaningful form for protecting human lives and social infrastructures" from the effects of disastrous seismic events (Hayakawa, 2018).

More than twenty years have passed since the Nature debate on earthquake prediction (introduced and concluded by Main, 1999a; Main, 1999b). The time passed since then apparently seems to justify the most "pessimistic (or skeptical) party" of that debate according to which earthquake prediction based on precursory signals is "impossible in principle" because of the chaotic and nonlinear nature of the seismic phenomenon (e.g., Geller et al., 1996; Matthews, 1997) or because "it is likely that an earthquake has no preparatory stage" (Kagan, 1997). As Uyeda and Nagao (2018) put it recently, "...because they could not identify reliable precursors, seismologists maintained a negative attitude toward earthquake prediction." This style of 
reasoning penetrated the consciousness of the scientific community so profoundly that it is explicitly expressed in Predicting the Unpredictable - the title of a book (Hough, 2010). Meanwhile, a number of large-magnitude earthquakes struck worldwide without being "predicted" and causing numerous victims and incommensurable economic losses such as the 2004 Sumatra earthquake $(227,898$ victims and US\$15 billion total damage; Telford and Cosgrave, 2006), the 2010 Haiti earthquake $(>100,000$ death toll and USD 7.8-8.5 billion economic loss; U.S. Geological Survey, 2013), and the 2011 Tohoku earthquake (15,900 victims and USD 360 billion economic loss; Bachev, 2014) that apparently confirmed the pessimistic view on earthquake prediction reinforced by a number of post-1999 papers. This pessimism has essentially lasted until today (Uyeda and Nagao, 2018).

However, there are still a few alternative expert views around (e.g., "there are increased amounts of data, new theories and powerful computer programs and scientists are using those to explore ways that earthquakes might be predicted in the future.", Blanpied, 2008). Developments in the domain of earthquake prediction research during the last few decades prompted by the occurrence of devastating seismic events worldwide seem to confirm such an optimistic view as mentioned by Uyeda and Nagao (2018) referring to "the recent remarkable revival of seismology in earthquake prediction research (...) emerged from the shadows of electromagnetic research.” Martinelli (2020) also noted that "some recent projects on earthquake precursors have produced interesting data recognized by the whole scientific community." Likewise, Hayakawa (2018) feels himself "very optimistic about the future of earthquake prediction."

On the other hand, one may question why all attempts in "predicting" earthquakes have failed so far or were not validated by the international scientific community: is it just because earthquake prediction is "impossible in principle" as most pessimists claim? Or, is "impossible in principle" the final and unquestionable answer to the precursor-based earthquake prediction problem? If not, then how an alternative solution may look like?

This article intends to discuss such questions and proposes a radically new approach to the issue of precursor-based earthquake prediction research strategy.

\section{A SHORT SUMMARY OF THE STATE OF THE ART IN EARTHQUAKE PREDICTION RESEARCH}

Jordan et al. (2011) evaluated the known "diagnostic precursors" (i.e., strain-rate changes, seismic velocity changes, electrical conductivity changes, radon emission, hydrogeological changes, electromagnetic signals, thermal anomalies, anomalous animal behavior, seismic patterns, and proxies for accelerating strain) individually, one-by-one, and found that none of them is universally valid concluding that "the search for diagnostic precursors has thus far been unsuccessful."
Crampin (2012) claimed that "in one case when seismic data from Iceland was being monitored online, the time, magnitude, and fault break of a $\mathrm{M}=5$ earthquake in Iceland was successfully stress-forecast three days before it occurred." However, this claimed prediction success "in one case," based on a single monitoring method, cannot be generalized as a universally valid solution applicable to all types of seismic events and all geodynamic environments.

As a consequence, the need for multiparameter monitoring of potential earthquake precursors emerged. It was increasingly invoked in the last 2 decades and researchers started coupling two or more monitored parameters in order to gain better confidence in their prediction efforts. Ryabinin et al. (2011), for example, studied together chlorine-ion concentration variations and geoacoustic emission in Kamchatka peninsula in boreholes within the same seismic zone claiming that they obtained significant anomalies "70 to 50 days before the earthquake for the hydrogeochemical data and at 29 and 6 days in advance for the geoacoustic data."

A recently (2018) published book (Pre-Earthquake Processes. A Multidisciplinary Approach to Earthquake Prediction Studies) edited by Dimitar Ouzounov, Sergey Pulinets, Katsumi Hattori, and Patrick Taylor resumes excellently the encouraging progress achieved in the research domain of earthquake prediction. However, the invoked positive results were rather disparate reflecting research efforts of individuals, small groups of researchers or, in the best case, national programs, such as those in China (Wang et al., 2018) or Taiwan (the iSTEP-1, two and three programs following the 1999 Chi-Chi earthquake, Tsai et al., 2018; Fu and Lee, 2018); they are essentially based on the most common approach of looking for the identification of universally valid precursors and considering only a small number of premonitory phenomena (different from country to country) in their respective multiparameter monitoring systems. Symptomatically, for instance, although biological sensors are mentioned as potential recorders of preseismic signals (e.g., Ouzounov et al., 2018a; Tramutoli et al., 2018b), none of the invoked monitoring systems considers them in their research programs. A common global research strategy concept is clearly lacking because, among other reasons, governmental opinions are different and changing over time. For instance, Iceland, Taiwan, China, Russian Federation, and Japan support researches oriented to possible earthquake forecasting, whereas the USA appears contradictory and Europe does not have a unique research policy.

Despite the encouraging results obtained in the last few decades in the field of earthquake prediction research, including a few alleged successful a priori predictions (e.g., using the $\mathrm{CN}$ seismicity pattern prediction algorithm, Peresan et al., 2012, Peresan, 2018, or using atmospheric-ionospheric precursors, Ouzounov et al., 2018b), no fully credible, validated, and generally accepted method emerged, as Jordan et al. (2011) put it: "the search for diagnostic precursors has not yet produced a successful short-term prediction scheme." Reviewing geofluid monitoring results, Martinelli (2020) also concluded that "earthquake prediction research based on parameters believed to be precursors of earthquakes is still controversial and still 
appear to be premature for the practical purposes demanded by governmental standards."

Most reported "successes" were "a posteriori" statements (i.e., "postpredictions") based on the post-factum recognition or retrospective tests of precursory signals related to particular seismic events (e.g., Shebalin et al., 2006; Papadopoulos et al., 2018; Fu and Lee, 2018; Zafrir et al. (2020), including some of the most devastating recent ones, e.g., Peresan, 2018; Tramutoli et al., 2018b).

Ouzounov et al. (2018b) presented noticeable results in devising a sound methodology to check the predictive potential of preearthquake signals based on a sensor web of several physical and environmental parameters (satellite thermal infrared radiation, electron concentration in the ionosphere, air temperature, and relative humidity). They claim success in the validation of different anomalous preearthquake signals in both retrospective $(3 \mathrm{M}>6$ events in the US, Taiwan, and Japan) and prospective ( $22 \mathrm{M}>5.5$ events in Japan) modes with a success rate of 21 out of 22 for the latter mode. However, one may question whether this methodology using just a small number of parameters registered by a few ground-based and satellite-held instruments can be generalized and considered valid for all types of earthquakes and all regional or local geodynamic environments.

Taking into consideration the above state of the art, this perspective article does not propose to review the burgeoning literature exhaustively on the subject of earthquake prediction. A number of recently published review articles (e.g., Martinelli, 2020) and books (e.g., Dimitar Ouzounov, Sergey Pulinets, Katsumi Hattori, and Patrick Taylor, eds, 2018) did that successfully. Rather, it focuses on the presentation of a possible strategic research approach based on a novel concept.

\section{CHALLENGING THE PESSIMISTIC VIEW ON THE EARTHQUAKE PREDICTION PROBLEM}

Science is about discovery. Discovering unknown features of nature is the foremost task of the natural sciences. Most scientific endeavors start by identifying unsolved problems. The scientists enrolled in such an adventure are interested, at least by genuine curiosity, to understand the unknown or unexplained. A lot of unknowns addressed by science were not solved and understood for a long time or during the lifetime of the generation that identified the problem. However, they remained in the collective scientific consciousness as something to be solved in the future, a challenge.

The history of science is rife with examples of universally accepted paradigms, equivalent with the "impossible in principle" statement, challenged by individuals and later recognized as viable. In Earth sciences, Wegener's hypothesis on the migration of continents was considered as "impossible in principle" (although not formulated with the same words). Likewise, flying with objects denser than air was explicitly declared "impossible in principle" just one hundred years ago even by leading scientists of the epoch.
The pessimists always argue that effort and money should not be spent for precursor-based earthquake prediction, given that all such efforts were unsuccessful in the past and, more importantly, because this is "impossible in principle"; rather, money should be spent for hazard mitigation programs. Leaving aside the fact that the two approaches are not mutually exclusive, one may wonder how other large-scale and costly research programs with uncertainties about their outcome comparable with possible earthquake prediction research programs were accepted for funding and are still ongoing for decades with no positive results. The NASA's SETI Program (run by the SETI Institute since 1994), for example, has spent more than USD $110 \mathrm{M}$ in the 1980-2005 time period (https://phys.org/news/2015-08-setiunprecedented.html) and is currently spending USD $2.5 \mathrm{M}$ yearly (https://geeknewscentral.com/2011/05/02/the-real-costof-seti/) with no relevant results. One may wonder, for good reasons, whether the chances of identifying extraterrestrial intelligence are higher than devising a reliable precursor-based earthquake prediction methodology. And, what is the relevance of both of them to society?

I conclude that precursor-based earthquake prediction should be viewed as a challenge rather than an insolvable (in principle) problem. Wyss (2001) expressed a similar view: "as a physical phenomenon, earthquakes must be predictable to a certain degree." Addressing the earthquake prediction problem as a challenge for science is mobilizing (intelligence, effort, time, and money), whereas looking at it as an "impossible in principle" task is demobilizing. As so, "perhaps, now is the time to discard the long-held pessimism and combine all our forces to venture toward transforming precursor information into practical earthquake prediction" (Uyeda and Nagao, 2018).

\section{WHY WAS PRECURSOR-BASED EARTHQUAKE PREDICTION UNSUCCESSFUL SO FAR?}

Despite a large number of (mostly post-factum) claims of successful earthquake prediction based on precursory phenomena such as radon anomalies (e.g., Crockett et al., 2006) or anomalous behavior of living creatures (e.g., Polyakov et al., 2015), the scientific community did not validate them so far. A classic example of claimed but not validated success is the 1975 Haicheng earthquake in China claimed by the Chinese scientists (Wang et al., 2006) as a successful prediction saving many lives. However, the prediction was just in the following year questioned by the devastating Tangshan earthquake ( $>240,000$ victims, USGS, 2013). The major lesson to be drawn is that no two earthquakes are alike. Therefore, the most frequently undertaken approach to predict earthquakes based on precursory signals by looking at, or monitoring, one single (or a few) parameter(s) of the presupposed precursory phenomenon, such as VAN, using merely electromagnetic parameters (Varotsos et al., 1986) does not work. There is no Holy Grail of a single, or a few, universally valid prediction signal to be surveyed at least because "it is practically impossible (...) to collect the large set of 
data for all parameters in real-time globally" (Pulinets et al., 2018).

Another reason is that individuals or small groups of researchers addressed the challenge of precursor-based earthquake prediction on their own, detached from a broader, national or international, systemic approach. As Wyss (2001) puts it, "no real program for earthquake prediction research exists in the United States (...) but motivated individuals are active". Also, "research connected with earthquake prediction has been characterized by the absence of great projects" (Martinelli, 2018). And this is, in my opinion, the cornerstone of the failure: the lack of a long-term strategy. Long ago, Frank Press (1968) complained that there is no research strategy in the US in the domain of earthquake prediction. Japan's investigation strategy, given as an example, was short-lived (10 years, Press, 1968), far less than what would have been necessary to obtain significant results. More recent successive short-term programs in Japan following the 1995 Kobe earthquake ended in remarkable results by retrospectively identifying electromagnetic precursors associated with ground movements (e.g., in the case of the 2011 M 9 Tōhoku megaearthquake); however, no currently running long-term program is founded (Hayakawa, 2018).

It is true that multisensor-/multiparameter-based research strategies are currently implemented in a number of earthquake disaster-prone countries, such as Turkey (Yuce et al., 2010), Russia (Pulinets et al., 2016), Japan (Hayakawa, 2018), China (Wang et al., 2018), Taiwan (Tsai et al., 2018), and Italy (Peresan, 2018); however, they are 1) part of local national programs, 2) unconnected to each other, hence lacking a common strategic concept, and 3) partial, i.e., considering only a few or a limited number of precursor types and corresponding parameters and sensors. The spectrum of "preearthquake phenomena" considered in China for its current multidisciplinary earthquake monitoring system, for instance, includes crustal deformation, seismicity, geoelectricity and geomagnetism and the behavior of crustal fluids (Wang et al., 2018), but no biological response. In Taiwan, the components of the multidisciplinary research on earthquake prediction include monitoring of microearthquake activities, crustal deformation, microgravity, geomagnetic total intensity, and geothermal water changes complemented with ionospheric data and statistical studies (Fu and Lee, 2018; Tsai et al., 2018). Pulinets et al. (2018) considered using only two groups of precursors, thermal and ionospheric "in order to simplify" the investigations.

Some limited-participation international projects were also initiated recently, such as the PRE-EARTHQUAKES project (EU-FP7cordis.europa.eu/result/rcn/57410_en.html) involving research institutions from Italy, Germany, Turkey, and Russia (Ouzounov et al., 2018b).

All of the research initiatives and strategies mentioned above are, however, different-in breath, philosophy, underlying concept, and international significance-from the strategic approach proposed in this article.

To summarize, despite some notable recent advancements, the precursor-based earthquake prediction research, as a whole, is generally considered unsuccessful so far (e.g., Wang et al., 2006; Uyeda and Nagao, 2018). This is, in my opinion, due to 1) the lack of long-term research strategy and related funding 2), the lack of large-scale international cooperation, 3) individualism of researchers/groups, aiming at finding the Holy Grail of earthquake prediction based on a single (or a few) signal of a single (or a few) precursory phenomenon, and, perhaps 4) the lack of high-level technical prerequisites (e.g., computing facilities and sensor technology). Therefore, any further approach to the problem has to be based on a strategy. A strategy, in turn, has to be based on a concept. A possible shift of paradigm from today's dominant pessimistic "impossible in principle" to an optimistic "yes, we can" needs a new concept.

\section{OUTLINES OF A POSSIBLE PARADIGM SHIFT IN PRECURSORY-BASED EARTHQUAKE PREDICTION RESEARCH}

\section{Conceptual Framework}

The basic principle of a possible new paradigm is the uniqueness of seismogenic structures. This trivial statement needs some explanations. Seismogenic structures are most commonly defined as active faults or fault segments. However, there are other structures that cannot be equated with faults, such as the Vrancea seismic zone in Romania (e.g., Radulian et al., 2000) that is rather a seismogenic volume of rocks of ca. $280,000 \mathrm{~km}^{3}$ having a surface-projected area of $70 \times 40 \mathrm{~km}$. Some "diffuse" seismogenic structures, such as those located in deep intraplate settings, are difficult to be defined, in the sense that their geometrical parameters (volume and outline) cannot be determined.

Irrespective of their nature, well-defined or not, those geological structures are "seismogenic" because they produce earthquakes. And they are unique. Each of them has its own particular geotectonic setting, unique mutual relationships with neighboring structures, unique internal composition and structure, unique seismic history, and a particular stress field.

As a consequence of their uniqueness, the seismogenic structures produce particular seismic events with typical features and parameters. Moreover, reequilibration after major events will cause modifications of the structure itself, so that the next events will take place in somewhat modified local conditions. However, one may suppose that seismogenic structures are stable enough in time (at least on the scale of human history) and that their basic features do not change and their general behavior is preserved.

Another consequence of the seismogenic structures' uniqueness and their consistent behavior in time is that any precursory phenomenology to be expected is also unique. Therefore, one should not expect the same precursory signal to be received from different seismogenic structures, not to mention any universally valid signals.

Although questioned, the concept of precursory phenomena is generally considered valid in the scientific community (e.g., Geller, 1991; Wyss, 2001). Theoretically, the sudden rupture/ slide produced by/in the seismogenic structure is preceded by stress accumulation and escalation, which, in turn, triggers modifications of the physical fields and chemical components 
(e.g., fluids) in the neighboring medium that propagate out from the critical zone in the form of geophysical and/or geochemical signals of various kinds. Those signals are, in principle, receivable at Earth's surface by adequately designed, tuned, and located sensors. Moreover, those propagating changes may trigger, by induction, modifications in other fields, with which they interact, hence generating secondary signals, for instance, in the atmosphere, ionosphere, and even the magnetosphere, through a complex coupling mechanism with the lithosphere, as Pulinets et al. (2018) and Hayakawa et al. (2018) convincingly demonstrated. As a consequence, an impending major seismic event may be preceded by a number of precursory signals of various kinds (physical, chemical, and biological), primary or induced.

Indeed, current research in China on "preearthquake phenomena" resulted in important findings (Wang et al., 2018). However, the use of those findings for actual preevent prediction (as opposed to postprediction) and warning meets enormous challenges, because of the complexity of the precursory phenomenology, since event location, time, and magnitude are to be "predicted", as Wang et al. (2018) put it, "this complexity may be due to differences in the tectonic environments around seismogenic zones". And, even more significantly, "the characteristics of the preearthquake phenomena preceding each event [of those monitored] differed," and "different geological structures and crustal environments are likely to produce different spatiotemporal patterns of pre-earthquake phenomena" (Wang et al., 2018). In other words, according to the terminology used in this article, this complexity and these differences arise because of the uniqueness of the seismogenic structures. Martinelli and Dadomo (2018) also arrived to the idea that not all seismogenic structures behave in the same manner as reflected in the fluid-related precursors: "Not all earthquakes seem to be preceded by detectable crustal strain changes in the epicentral area and this could explain the lack of fluid -related precursors." Hayakawa et al. (2018), searching for preseismic ionospheric perturbations found that "with earthquake depths of $>40 \mathrm{~km} \mathrm{(..)} \mathrm{there} \mathrm{is} \mathrm{no} \mathrm{clear} \mathrm{precursory} \mathrm{signal} \mathrm{evident."}$ Parrot and Li (2018) also emphasized that "it cannot be excluded that a [precursory] mechanism could be efficient in a given seismic area and not in another one." Ouzounov et al. (2018a) explicitly recognized that "no solitary existing method (...) can provide successful and consistent short-term forecasting on a global scale. This is most likely because of the local geology...." Furthermore, "it is difficult to determine the location of the epicenter of a major event based only on recorded observations of pre-earthquake phenomena" (Wang et al., 2018). Considering the concept proposed here (i.e., addressing "preearthquake phenomena" at/for particular individual seismogenic structures), this latter type of shortcomings is automatically eliminated.

The common sense statements, and the copiously cited examples, presented above, all converge toward the acceptance of the uniqueness of seismogenic structures, which, in turn leads to the derived concept of precursory fingerprint. Each seismogenic structure, in particular those well-defined (in terms of nature, stress field, and size/volume), might have its unique assemblage of precursory phenomena, each of them being associated with a particular type of signal propagating through the surrounding medium. As a consequence, an earthquake prediction researcher may consider a particular assemblage of precursory signals for every particular seismogenic structure, which is the unique precursory fingerprint of that unique seismogenic structure. The task is to find that precursory fingerprint of the studied seismogenic structure. How would a strategy that takes this task seriously look like?

\section{Outlines of a Possible Internationally Coordinated Research Strategy}

The conceptual framework of the envisaged strategy involves two postulates: 1) precursory signals do exist and they are detectable in principle; 2) the concept of precursory fingerprint of individual seismic structures is valid. Instead of looking for universally valid precursors, the strategy targets a less ambitious goal: identifying the precursory fingerprint of individual seismic structures, hence having a merely local validity (as a starting assumption). The precursory fingerprint has to be found at as many individual seismic structures as possible, ideally covering all types of tectonic regimes and stress field. This is achievable by monitoring selected well-known structures worldwide at purposefully designed and adequately equipped observatories hosting a wide range of sensors of the highest-resolution currently available covering all possible types of precursory signals (seismic, physical, chemical, and biological) in order to assure a multisensor/ multiparameter monitoring system. It is worth noting that because "a majority of the reported earthquake precursor data found during the past few decades have been proven to be nonseismological (mainly electromagnetic)" (Hayakawa, 2018), the electromagnetic component of that part of the monitoring system considers that physical precursors must be adequately represented in the research programs including ground-based and satellite-held instruments (e.g., those on-board the currently active French DEMETER satellite, Parrot and Li, 2018) in order to understand the effects of lithosphere-atmosphere-ionospheremagnetosphere coupling (e.g., Hattori and Han, 2018; Hayakawa, 2018; Hayakawa et al., 2018; Pulinets et al., 2018) at the local scale. Preseismic atmospheric thermal anomalies are among those signals able to be effectively detected by satelliteheld instruments (Ouzounov et al., 2018a; Tramutoli et al., 2018a). Fu and Lee (2018) also advocate for a "systematic characterization of all possible precursors" that "may help us." Tramutoli et al., 2018b, based on a reach literature, listed a large number of precursors, identified (mostly post-factum!) at various locations as preceding strong earthquakes, during the manydecade-long modern history of earthquake prediction research: deformation, geochemical, thermal infrared, latent head, earthquake clouds and lights, air temperature and humidity, atmospheric pressure, VHF and VLF signals, and GPSassociated total electron content; interestingly, biological precursors are missing from that list. The potential benefits of "geofluid monitoring" (including hydrogeologic measurements and geochemical analyses) of earthquake-prone areas were recently discussed in great detail by Martinelli (2020) as part 
of the research arsenal in the quest for diagnostic precursors. Ongoing geofluid monitoring research is mentioned by the same author at test sites located in China, Iceland, Japan, the Russian Federation, Taiwan, and the USA. However, he warns about the inherent limitations of that type of research: "in principle, all earthquakes occurring in compressional tectonic regimes cannot be forecasted by geofluid monitoring."

Therefore, there is an extremely rich "offer" of virtual preearthquake phenomena, and related parameters, to be observed/measured and monitored, of which an n-sized sensor matrix can be completed.

Once installed, a matrix of $n$ (say, 50) different sensors, measuring many more (say 80) parameters, will monitor each selected structure trying to capture precursory signals preceding a potentially destructive earthquake. One may suppose that only a few (say, four of the 50) sensors will be activated with eight measured parameters before imminent seismic events and only above a certain magnitude threshold (also characteristic of the monitored structure) depending on the sensors' sensitivity. The number and type of activated sensors and above-the-threshold parameters would provide the precursory fingerprint of the individual seismic structure. Experts of each precursory phenomenon may establish the significant threshold values of the monitored parameters (e.g., following Shebalin et al., 2006) to distinguish signal from noise and anomalous behavior from background activity. Artificial intelligence and machine learning involving pattern-recognizing algorithms (Shebalin et al., 2006, and references within) can also be implemented to evaluate sensor activity. Such extremely powerful modern computing tools are able not only to process and evaluate the response of certain sensors but also to point out complex correlation patterns of sensor responses. Boxberger et al. (2017), for instance, concluded that the innovative "multiParameter Wireless Sensing system allows different sensor types to be combined with h-high-performance computing and communication components."

Such an endeavor involves large-scale international effort, leadership, coordination, and funding of decades-long observations (Wyss, 1997: "long-term data sets are needed to make progress in earthquake prediction research"), measurements, and experiments, as Wyss (2001) envisaged that "leadership is necessary to raise the funding to an adequate level and to involve the best minds in this promising, potentially extremely rewarding, but controversial research topic."

The leadership can be assumed by IUGG's IASPEI Commission that already had some sparse initiatives in this sense, as follows.

Resolution 1 of IASPEI RESOLUTIONS adopted at the closing plenary meeting in Santiago, Chile (October 2005), on an International Active-Monitoring Network expressed the need for international cooperation in this domain with the following words: "IASPEI encourages the formation of an International Network of Active Monitoring Test Sites in order to facilitate collaborative seismic and geoelectrical studies of crustal deformation; active monitoring of seismically active zones, and exchange of technical information, data and personnel" (IASPEI, 2020).
Of the 14 IASPEI Resolutions and Statements in the period 1991-2017 (IASPEI, 2020), two explicitly address earthquake prediction issues by recommending the "establishment of a global network of Test Areas for Earthquake Prediction corresponding to the major types of geotectonic settings: Kamchatka (platesubduction), Iceland (plate spreading), Yunnan, China (intercontinental strike-slip), Gulf of Corinth, Greece (continental rifting) and Beijing (intra-continental) and it "urges all nations to collaborate to extend coverage to the full globe, and recommends its Commissions and Committees to pursue the task in the years ahead" (ftp://ftp.iaspei.org/pub/resolutions/resolutions_1997_

thessaloniki.pdf).

Likewise, of the 14 ESC (European Seismological Commission) business meetings (1996-2015) (http://www.esc-web.org/minutes-ofesc-meetings.html), a few (http://www.esc-web.org/minutes-of-escmeetings/79-european-seismological-commission/88-esc-buisnessmeeting-reykjavik-iceland-september-12-1996.html; Reykjavik, 1996; http://www.esc-web.org/minutes-of-esc-meetings/79-europeanseismological-commission/88-esc-buisness-meeting-reykjavikiceland-september-12-1996.html; Tel Aviv, 1998) (http://www. esc-web.org/minutes-of-esc-meetings/79-european-seismologicalcommission/90-esc-buisness-meeting-tel-aviv-1998.html) addressed explicitly earthquake prediction issues expressing the need for international cooperation.

Although disparate so far and without being based on a unique strategic concept, such initiatives are valuable precedents worthy of being followed and enhanced in a much consequent manner to assure international professional guidance and leadership for the implementation of a global earthquake precursor research strategy such as that proposed here.

The long-term strategy involves three phases: 1) experimental, 2) validation/extension, and 3) implementation.

The experimental phase (or "learning stage," acc. to Peresan, 2018) aims at checking the validity of the precursory fingerprint concept by setting up a small number of observatories at/near the best-studied seismic structures worldwide, each equipped with a matrix of as many kinds of sensors as possible in consensus with Birkhäuser's (2004) statement: "progress in earthquake science and prediction over the next few decades will require increased monitoring in several active areas." Sensors designed to capture primary and/or induced precursory signals will measure a high number of parameters, combined with an array of seismographs detecting changes in background seismicity (Sammis and Sornette, 2002; Shebalin et al., 2006; Peresan, 2018) to recognize foreshock activity (Papadopoulos et al., 2018). Other sensors are destined to point out subtle changes of the physical parameters (e.g., temperature, mass-flux, and gas flow rate fluctuations) and composition of fluids (dissolved ions, dissolved gases, soil gas, $\mathrm{CO}_{2}, \mathrm{CH}_{4}, \mathrm{He}, \mathrm{H}$, radon, and thoron) (Zoran et al., 2012; Oh and Kim, 2015; Martinelli, 2020) circulating in the crust (e.g., Tsunogai and Wakita, 1995; Claesson et al., 2004; Hartman et al., 2005; Fu and Lee, 2018; Martinelli and Dadomo, 2018). Ground deformation and other space-monitorable atmospheric and ionospheric signals (e.g., Sgrigna et al., 2007; Hayakawa et al., 2018; Tramutoli et al., 2018a) might be considered to complete the ground-based monitoring system. Still other sensors will monitor the 
behavior of living creatures under stress conditions induced by changes in their physical and chemical environment due to an impending megaseismic event. Biological sensors may include all levels of organization across the biosphere, from bacteria to the human sensor (e.g., Polyakov et al., 2015), including vegetal life.

In the experimental phase, laboratory investigations are also needed in specialized high-performance labs in order to devise and check adequate sensors, i.e., to check the capability of various instruments and methods to be used as seismic sensors, including living organisms as potential biological sensors. Innovative approaches are welcome. A worldwide network of laboratories performing experimental work on precursor-sensitive instruments and methods would be required. New enhancedsensitivity sensors resulting from the lab investigations will be implemented and tested at the monitoring observatories.

Another set of experiments aims at identifying the most suitable sensor emplacement sites for certain types of parameters to be monitored. It might be based on the recognition that not all Earth surface points are equivalent in terms of signal-receiver capability. In other words, certain types of sensors have to be emplaced at locations where the signal/noise ratio is the highest in the vicinity of the targeted seismogenic structure. One may speculate that those most "sensitive sites" are located at the endpoints of signal transmission trajectories along which the energy/information loss of the precursory signal is minimal. For instance, crust-crossing volcanic conduits with no intervening magma-chambers may serve as upside-down antennas (waveguides) for signal transmission (Szakács, 2011), given that any possible geophysical signal will travel faster and with less loss of information energy along such a more homogenous medium than along any other crustal trajectory. Likewise, deep crustal fractures are privileged transmission paths for fluids-carrying geochemical signals. For example, in recent years, several multiparameter continuous soil gas and gamma-ray monitoring stations have been deployed in Taiwan, "strategically located near active faults" (Tsai et al., 2018). Likewise, Fu and Lee (2018) found that "the Rn precursory anomalies were not observed at all the stations because the crust was not homogeneous" (i.e., some of the stations are located in "sensitive" sites, whereas others are not). Martinelli and Dadamo (2018) also state, citing a number of previous works, that "possible geochemical and hydrogeologic precursors have been observed hours to months before some strong earthquakes in 'sensitive' monitoring sites among many insensitive sites." Martinelli (2020) reiterated the idea of monitoring location sensitivity in his review article: "sensitive locations [for geofluid monitoring] are generally found along active faults, in thermal springs, or in deep wells that reach confined reservoirs capable of acting as natural strain meters.”

Therefore, in the experimental phase, purpose-oriented and interdisciplinary investigations are also needed to identify and map the most suitable sensor emplacement sites.

The duration of the experimental phase depends on the seismic activity of the monitored structures: at least one highmagnitude event has to occur in order to evaluate the effectiveness of the monitoring system and to find out whether the observed structure produced significant precursory signals detected by the sensor matrix or not. In other words, can that particular seismic structure be characterized by a specific precursory fingerprint or not?

In the most optimistic scenario, the expected outcome of the experimental phase would be the emergence of a reliable methodology to identify the precursory fingerprint of at least part of the monitored structures. In the case no such result is obtained for none of the observed structures, one has to evaluate whether the precursory fingerprint project has to be abandoned or continued at least until the next megaseismic event occurs.

In the validation/extension phase-following the experimental phase only if considered successful or, at least, meaningful-the experience gained during the first phase will be extended to more seismic structures worldwide in order to 1) validate the results at other structures similar to those where the experiments were successful and 2) enhance and refine the multiparameter sensor matrix for those structures where negative results were obtained in the experimental phase maintaining the monitoring observatories instead of being dismantled. Again, this phase's duration depends on the occurrence of major earthquakes.

The implementation stage will consider only those seismic structures where the first two stages provided positive results (where the characteristic precursory fingerprint was readily identified). As a result, a worldwide network of multiparameter monitoring stations will be operational at a number of well-known seismic structures, including part of those of the highest hazard and risk. The multiparameter monitoring system will be rationalized and optimized by eliminating the inert (i.e., nonresponsive) infrastructure from the sensor matrix. Instead, the sensitivity of the remaining sensors will be continuously improved through further onsite experimental work and the results shared with all active monitoring stations worldwide.

\section{DISCUSSION}

Attempts of setting up monitoring systems in order to detect seismic precursory signals are not without precedents as Martinelli (2020) has shown. However, they were territorially limited to particular countries, such the Soviet Union and China, and to a particular time, e.g., 1970-1990 in the Soviet Union (Martinelli, 2020), all prompted by the occurrence of damaging earthquakes in the surveyed area. Such efforts were basically national endeavors uncoordinated internationally or not based on an underlying strategic concept other than the desire to identify universally valid individual, or a group of "key" (i.e., diagnostic, acc. to Jordan et al., 2011) precursors.

It is possible that the final outcome of the multidecadal research effort based on the strategy sketched above will result in a small number of seismogenic structures whose precursory fingerprints are readily identified and where a reliable monitoring system is implemented based on an optimized sensor matrix. The worst scenario implies that no such case will be found. In that case, the whole project will be abandoned and no more money will be invested in it. In the most optimistic scenario, the precursory fingerprint of a significant number of seismogenic 
structures will be found. Moreover, one may envisage that some kind of regularity of the identified precursory fingerprints will be revealed. For instance, it would turn out that a particular kind of stress regime or a particular genetic type of earthquakes manifests itself via a particular and recognizable type of precursory fingerprint, allowing the generalization of the findings over other structures belonging to the same class. Patternrecognizing artificial intelligence would help in sorting and evaluating the results in the most optimistic outcome scenario. More innovative approaches, such as machine learning, as RouetLeduc et al. (2017) reported for laboratory earthquakes, using time-series datasets gathered at monitoring stations, might be implemented for information evaluation.

The final outcome of the proposed scientific endeavor, its benefits in terms of new knowledge and research methodology, is comparable with other large-scale scientific adventures of humankind (such as the SETI program) at a similar or lower cost and with a similar, if not higher, chance of success. In contrast, the pessimistic approach to the earthquake prediction puzzle (i.e., the "impossible in principle" postulate, which posits that any effort to solve it is futile) is of no benefit for science.

These conclusions are fully consistent with those of Wyss (2001) who stated that "earthquake prediction is difficult but not impossible," "we must exercise patience and not expect spectacular success quickly," and any expectations are

\section{REFERENCES}

Bachev, H. (2014). Impacts of March 2011 earthquake, tsunami and Fukushima nuclear accident in Japan. SSRN Electron. J. 125. doi:10.2139/ssrn.2538949

Birkhäuser, B. (2004). Rethinking earthquake prediction. Pure Appl. Geophys. 155 (2-4), 207-232. doi:10.1007/978-1-4020-4399-4_106

Blanpied, M. (2008). Can we predict earthquakes? USGS CoreCast. Available at: http://www.usgs.gov/corecast/details.asp?ID=76 (Accessed May 20, 2008).

Boxberger, T., Fleming, K., Pittore, M., Parolai, S., Pilz, M., and Mikulla, S. (2017). The multi-parameter wireless sensing system (MPwise): its description and application to earthquake risk mitigation. Sensors. 17, 10. doi:10.3390/ s17102400

Claesson, L., Skelton, A., Graham, C., Dietl, C., Mörth, M., Torssander, P., et al. (2004). Hydrogeochemical changes before and after a major earthquake. Geology. 32 (8), 641-644. doi:10.1130/G20542.1

Crampin, S. (2012). Comment on the report "operational earthquake forecasting" by the international commission on earthquake forecasting for civil protection. Ann. Geophys. 55, 1. doi:10.4401/ag-5516

Crockett, R. G., Gillmore, G. K., Phillips, P. S., Denman, A. R., and Groves-Kirkby, C. J. (2006). Radon anomalies preceding earthquakes which occurred in the UK, in summer and autumn 2002. Sci. Total Environ. 364 (1-3), 138-148. doi:10. 1016/j.scitotenv.2005.08.003

$\mathrm{Fu}$, Ch.-Ch., and Lee, L.-Ch. (2018). "Continuous monitoring of fluid and gas geochemistry for seismic study in taiwan," in Pre-earthquake Processes. a multidisciplinary approach to earthquake prediction studies.. Editors D. Ouzounov, S. Pulinets, K. Hattori, and P. Taylor (John Wiley \& Sons), 199-218.

Geller, R. J. (1991). Unpredictable earthquakes. Nature. 353, 612.

Geller, R. J., Jackson, D. D., Kagan, Y. Y., and Mulargia, F. (1996). Earthquakes cannot be predicted. Science. 275, 5306, 1616. doi:10.1126/science.275.5306. 1616

Hartmann, J., Berner, Z., Stüben, D., and Henze, N. (2005). A statistical procedure for the analysis of seismotectonically induced hydrochemical signals: a case unrealistic "unless the field of prediction research is reformed and well-funded."

\section{DATA AVAILABILITY STATEMENT}

The original contributions presented in the study are included in the article/Supplementary Material, further inquiries can be directed to the corresponding author.

\section{AUTHOR CONTRIBUTIONS}

The author confirms being the sole contributor of this work and has approved it for publication.

\section{ACKNOWLEDGMENTS}

Ágnes Gál is thanked for her help in acquiring up-to-date literature on the subject. Simona Szakács helped to improve the English expression of the text. Two reviewers are acknowledged for their thoughtful comments on the early version of the manuscript. Giovanni Martinelli, Antonella Peresan, and Ying Li contributed to improving the final version of the manuscript with their valuable comments and recommendations.

study from the Eastern Carpathians, Romania. Tectonophysics. 405, 77-98. doi:10.1016/j.tecto.2005.05.014

Hattori, K., and Han, P. (2018). "Statistical analysis and assessment of ultralow frequency magnetic signals in Japan as potential earthquake precursors," in Preearthquake processes. a multidisciplinary approach to earthquake prediction studies. Editors D. Ouzounov, S. Pulinets, K. Hattori, and P. Taylor (John Wiley \& Sons), 229-240.

Hayakawa, M., Asano, T., Rozhnoi, A., and Solovieva, M. (2018). "Very-low- to low-frequency sounding of ionospheric perturbations and possible association with earthquakes," in Pre-earthquake processes. a multidisciplinary approach to earthquake prediction studies. Editors D. Ouzounov, S. Pulinets, K. Hattori, and P. Taylor (John Wiley \& Sons), 277-304.

Hayakawa, M. (2018). "Earthquake precursor studies in Japan," in Preearthquake processes. a multidisciplinary approach to earthquake prediction studies. Editors D. Ouzounov, S. Pulinets, K. Hattori, and P. Taylor (John Wiley \& Sons), 7-18.

Hough, S. (2010). Predicting the unpredictable. The tumultuous science of earthquake prediction. Princeton: Princeton University Press, 280.

IASPEI (2020). Resolutions \& statements. Available at: http://www.iaspei.org/ documents/resolutions-statements (Accessed October 2020).

Jordan, T. H., ChenGasparini, Y.-T. P., Madariaga, R., Main, I., Marzocchi, W., Papadopoulos, G., et al. (2011). Operational Earthquake forecasting. state of knowledge and guidelines for utilization. Report by the International Commission on earthquake forecasting for civil protection. Istituto Nazionale di Geofisica e Vulcanologia. Ann. Geophys. 54 (4), 391.

Kagan, Y. Y. (1997). Are earthquakes predictable?. Geophys. J. Int. 131 (3), 505-525. doi:10.1111/j.1365-246X.1997.tb06595.x

Kelman, I. (2019). Axioms and actions for preventing disasters. Prog. Disaster Sci. 2, 100008. doi:10.1016/j.pdisas.2019.100008.

Main, I. (1999a). Is the reliable prediction of individual earthquakes a realistic scientific goal? Nature. doi:10.1038/nature28107

Main, I. (1999b). Earthquake prediction: concluding remarks. Nature. doi:10.1038/ nature 28133 
Martinelli, G. (2020). Previous, current, and future trends in research into earthquake precursors in geofluids. Geosciences. 10, 189. doi:10.3390/ geosciences 10050189

Martinelli, G. (2018). "Contributions to a history of earthquake prediction research," in Pre-earthquake processes. a multidisciplinary approach to earthquake prediction studies. Editors D. Ouzounov, S. Pulinets, K. Hattori, and P. Taylor (John Wiley \& Sons), 67-76.

Martinelli, G., and Dadomo, A. (2018). "Geochemical and fluid-related precursors of earthquakes: previous and ongoing research trends," in Pre-earthquake processes. a multidisciplinary approach to earthquake prediction studies. Editors D. Ouzounov, S. Pulinets, K. Hattori, and P. Taylor (John Wiley \& Sons), 219-228.

Matthews, R. A. J. (1997). Decision-theoretic limits on earthquake prediction. Geophys. J. Int. 131 (3), 526-529. doi:10.1111/j.1365-246X.1997.tb06596.x.

Oh, H. Y., and Kim, G. (2015). A radon-thoron isotope pair as a reliable earthquake precursor. Sci. Rep. 5, 13084. doi:10.1038/srep13084

Ouzounov, D., Pulinets, S., Kafatos, M. C., and Taylor, P. (2018a). "Thermal radiation anomalies associated with major earthquakes," in Pre-earthquake processes: a multidisciplinary approach to earthquake prediction studies. Editors D. Ouzounov, S. Pulinets, K. Hattori, and P. Taylor (John Wiley \& Sons), 259-274.

Ouzounov, D., Pulinets, S., Liu, J.-Y., Hattori, K., and Han, P. (2018b). "Multiparameter assessment of pre-earthquake atmospheric signals," in Pre-earthquake processes: a multidisciplinary approach to earthquake prediction studies. Editors D. Ouzounov, S. Pulinets, K. Hattori, and P. Taylor (John Wiley \& Sons), 339-359.

Papadopoulos, G., Minadakis, G., and Orfanogiannaki, K. (2018). "Short-term foreshocks and earthquake prediction," in Pre-earthquake processes: a multidisciplinary approach to earthquake prediction studies. Editors D. Ouzounov, S. Pulinets, K. Hattori, and P. Taylor (John Wiley \& Sons), 127-147.

Parrot, M., and Li, M. (2018). "Statistical analysis of the ionospheric density recorded by the DEMETER satellite during seismic activity," in Pre-earthquake processes: a multidisciplinary approach to earthquake prediction studies. Editors D. Ouzounov, S. Pulinets, K. Hattori, and P. Taylor (John Wiley \& Sons), 319-328.

Peresan, A., Kossobokov, V., and Panza, G. F. (2012). Operational earthquake forecast/ prediction. Rend. Fis. Acc. Lincei. 23, 131-138. doi:10.1007/s12210-012-0171-7

Peresan, A. (2018). "Recent developments in the detection of seismicity patterns for the Italian region," in Pre-earthquake processes. a multidisciplinary approach to earthquake prediction studies. Editors D. Ouzounov, S. Pulinets, K. Hattori, and P. Taylor (John Wiley \& Sons), 149-171.

Polyakov, Y. S., Ryabinin, G. V., Solovyeva, A. B., and Timashev, S. F. (2015). Is it possible to predict strong earthquakes? Pure Appl. Geophys. 172 (7), 1945-1957.

Press, F. (1968). A strategy for an earthquake prediction research program. Tectonophysics. 6 (1), 11-15. doi:10.1016/0040-1951(68)90022-X

Pulinets, S., Ouzounov, D., Karelin, A., and Davidenko, D. (2018). "Lithosphere-atmosphere-ionosphere-magnetosphere coupling-a concept for pre-earthquake signals generation," in Pre-earthquake processes: a multidisciplinary approach to earthquake prediction studies. Editors D. Ouzounov, S. Pulinets, K. Hattori, and P. Taylor (John Wiley \& Sons), 79-98.

Pulinets, S., Ouzounov, D., and Petrukhin, A. (2016). Multiparameter monitoring of short-term earthquake precursors and its physical basis. implementation in the Kamchatka region. E3S Web Conf. 11, 00019. 10. 1051/e3sconf/20161100019

Radulian, M., Mandrescu, N., Panza, G. F., Popescu, E., and Utale, A. (2000). Characterization of seismogenic zones of Romania. Pure Appl. Geophys. 157, 57-77. doi:10.1007/PL00001100.

Rouet-Leduc, B., Hulbert, C., Lubbers, N., Barros, K., Humphreys, C. J., and Johnson, P. A. (2017). Machine learning predicts laboratory earthquakes. Geophys. Res. Lett. 44, 9276-9282. doi:10.1002/2017GL074677.

Ryabinin, G. V., Polyakov, Yu. S., Gavrilov, V. A., and Timashev, S. F. (2011). Identification of earthquake precursors in the hydrogeochemical and geoacoustic data for the Kamchatka peninsula by flicker-noise spectroscopy. Nat. Hazards Earth Syst. Sci. 11, 541-548. doi:10.5194/ nhess-11-541-2011

Sammis, C. G., and Sornette, D. (2002). Positive feedback, memory, and the predictability of earthquakes. Proc. Natl. Acad. Sci. U.S.A. 99 (Suppl. 1), 2501-2508. doi:10.1073/pnas.012580999

Sgrigna, V., Buzzi, A., Conti, L., Picozza, P., Stagni, C., and Zilpimiani, D. (2007). Seismo-induced effects in the near-earth space: combined ground and space investigations as a contribution to earthquake prediction. Tectonophysics. 431 (1-4), 153-171. doi:10.1016/j.tecto.2006.05.034
Shebalin, P., Keilis-Borok, V., Gabrielov, A., Zaliapin, I., and Turcotte, D. (2006). Short-term earthquake prediction by reverse analysis of lithosphere dynamics. Tectonophysics. 413, 63-75. doi:10.1016/j.tecto.2005.10.033

Szakács, A. (2011). Earthquake prediction using extinct monogenetic volcanoes: a possible new research strategy. J. Volcanol. Geotherm. Res. 201, 404-411. doi:10. 1016/j.jvolgeores.2010.06.015.

Telford, J., and Cosgrave, J. (2006). Tsunami evaluation coalition: synthesis report. London: TEC. Available at: https://www.sida.se/contentassets/ f3e0fbc0f97c461c92a60f850a35dadb/joint-evaluation-of-the-international-responseto-the-indian-ocean-tsunami_3141.pdf (Accessed March 2020).

Tramutoli, V., Filizzola, C., Genzano, N., and Lisi, M. (2018a). "Robust satellite techniques for detecting preseismic thermal anomalies," in Pre-earthquake processes: a multidisciplinary approach to earthquake prediction studies. Editors D. Ouzounov, S. Pulinets, K. Hattori, and P. Taylor (John Wiley \& Sons), 243-258.

Tramutoli, V., Genzano, N., Lisi, M., and Pergola, N. (2018b). "Significant cases of preseismic thermal infrared anomalies," in Pre-earthquake processes. a multidisciplinary approach to earthquake prediction studies. Editors D. Ouzounov, S. Pulinets, K. Hattori, and P. Taylor (John Wiley \& Sons), 331-338.

Tsai, Y-B., Liu, J. Y., Shin, T.-C., Yen, H.-Y., and Chen, C.-H. (2018). "Multidisciplinary earthquake precursor studies in taiwan: a review and future prospects," in Pre-earthquake processes. a multidisciplinary approach to earthquake prediction studies. Editors D. Ouzounov, S. Pulinets, K. Hattori, and P. Taylor (John Wiley \& Sons), 41-65.

Tsunogai, U., and Wakita, H. (1995). Precursory chemical changes in ground water: Kobe earthquake, Japan. Science. 269, 61-63. doi:10.1126/science.269.5220.61

U.S. Geological Survey (2013). Earthquakes with 50,000 or more deaths. Archive. Available at: http://earthquake.usgs.gov/earthquakes/world/most_destructive. php (Accessed March 2013).

Uyeda, S., and Nagao, T. (2018). "International cooperation in pre-earthquake studies: history and new directions," in Pre-earthquake processes. a multidisciplinary approach to earthquake prediction studies. Editors D. Ouzounov, S. Pulinets, K. Hattori, and P. Taylor (John Wiley \& Sons), 3-6.

Varotsos, P., Alexopoulos, K., Nomicos, K., and Lazaridou, M. (1986). Earthquake prediction and electric signals. Nature. 322, 120. doi:10.1038/322120a0

Wang, H., Zhang, Y., Liu, J., Shen, X., Yu, H., Jiang, Z., et al. (2018). "Pre-earthquake observations and their application in earthquake prediction in China: a review of historical and recent progress," in Pre-earthquake processes. a multidisciplinary approach to earthquake prediction studies. Editors D. Ouzounov, S. Pulinets, K. Hattori, and P. Taylor (John Wiley \& Sons), 19-39.

Wang, K., Chen, Q. F., Shihong, S., and Wang, A. (2006). Predicting the 1975 Haicheng earthquake. Bull. Seismol. Soc. Am. 96 (3), 757-795. doi:10.1785/ 0120050191.

Wyss, M. (1997). Second round of evaluations of proposed earthquake precursors. Pure Appl. Geophys. 149, 3-16. doi:10.1007/BF00945158.

Wyss, M. (2001). Why is earthquake prediction research not progressing faster? Tectonophysics. 338 (3-4), 217-223. doi:10.1016/S0040-1951(01)00077-4

Yuce, G., Ugurluoglu, D., Adar, N., and Oeser, V. (2010). Monitoring of earthquake precursors by multi-parameter stations in Eskisehir region (Turkey). Appl. Geochem. 25 (4), 572-579. doi:10.1016/j.apgeochem.2010.01.013

Zafrir, H., Barbosa, S., Levintal, E., Weisbrod, N., Horin5, Y. B., and Zalevsky, Z. (2020). The impact of atmospheric and tectonic constraints on radon-222 and carbon dioxide flow in geological porous media-a dozen-year research summary. Front. Earth Sci. 8, 433. doi:10.3389/feart.2020.559298

Zoran, M., Savastru, R., Savastru, D., Chitaru, C., Baschir, L., and Tautan, M. (2012). Monitoring of radon anomalies in South-Eastern part of Romania for earthquake surveillance. J. Radioanal. Nucl. Chem. 293, 769-781. 10.1007/ s10967-012-1780-4.

Conflict of Interest: The author declares that the research was conducted in the absence of any commercial or financial relationships that could be construed as a potential conflict of interest.

Copyright () 2021 Szakács. This is an open-access article distributed under the terms of the Creative Commons Attribution License (CC BY). The use, distribution or reproduction in other forums is permitted, provided the original author(s) and the copyright owner(s) are credited and that the original publication in this journal is cited, in accordance with accepted academic practice. No use, distribution or reproduction is permitted which does not comply with these terms. 